\title{
FRIGHETTO, Renan. A Antiguidade Tardia: Roma e as monarquias romano-bárbaras numa época de transformações (Séculos II - VIII). Curitiba: Juruá, 2012.
}

\author{
Josip Horus Giunta Osipi ${ }^{1}$
}

Publicado no ano de 2012, o livro A Antiguidade Tardia: Roma e as monarquias romano-bárbaras numa época de transformações (Séculos II - VIII), escrito por Renan Frighetto ${ }^{2}$, é o resultado de 25 anos de estudo e especialização do autor, que realizou um mestrado na área de História Antiga e Medieval (UFRJ, 1990) e um doutorado em História Antiga (Universidad de Salamanca, 1996). Frighetto, quando do lançamento do livro, já fora autor de dois livros e mais de 40 publicações de artigos e capítulos de livros no Brasil e no exterior. Especialista em Antiguidade Tardia, Frighetto atua como Professor Permanente do Programa de Pós-Graduação da UFPR, professor associado de graduação da UFPR e também na linha de pesquisa Cultura e Poder desde 1998. É participante do NEMED, Núcleo de Estudos Mediterrânicos da UFPR, onde desenvolve suas pesquisas.

Renan Frighetto, em sua obra, se junta ao coro de notáveis historiadores que muito contribuíram para o desenvolvimento e defesa do conceito de antiguidade tardia, como Peter Brown, Henri Irineé Marrou,

\footnotetext{
${ }^{1}$ Estudante de História - Licenciatura e Bacharelado na UFPR.

2 Mais informações sobre o autor disponíveis em seu currículo Lattes (http://lattes.cnpq.br/4817986767304134).
} 
Jean-Michel Carrié, dentre outros. Tal conceito não é universalmente aceito pela academia, uma vez que parte de uma perspectiva diferente na abordagem do período em questão (séculos II - VIII). Por isso, Frighetto, em introdução ao livro, descreve o conceito de Antiguidade Tardia, com um breve histórico de seu desenvolvimento e seus principais temas e abordagens.

Na introdução do livro, A Definição de Antiguidade Tardia: Espaço e Tempo, Frighetto situa seu trabalho numa obra maior, e explica sucintamente diversos aspectos que caracterizam a Antiguidade Tardia como um período singular. Para isso, o autor aborda questões de caráter principalmente político, institucional e ideológicos. O período trabalhado no livro é, de acordo com o autor, não um período de crise e decadência sócio-política, mas sim uma época de intensas transformações nos âmbitos já citados; trata-se, portanto, de um período marcado pela "Reformulação, readequação e interação: três conceitos que fazem da Antiguidade Tardia um período histórico único, autônomo e dotado de identidade própria” (FRIGHETTO, 2009, p. 121).

A Antiguidade Tardia, segundo o autor, é também um período de intensas interações entre romanos e outros povos bárbaros. Tal interação foi marcada não somente por guerras e sobreposições culturais e militares, mas muito mais por um intercâmbio constante de pessoas, políticas, culturas, entre outros. Deste modo, não se observa, durante a Antiguidade Tardia, uma decadência cultural e social do Império Romano necessariamente, mas muito mais a formação paulatina de uma nova civilização romano-bárbara. 
No âmbito religioso, Frighetto aponta para a crescente importância da religião - pagã, e depois também cristã - como base ideológica para a legitimação dos poderes imperiais e régios, principalmente depois dos éditos de liberdade religiosa no início do Século IV.

Apesar de a crise do Império Romano tradicionalmente ser relacionada ao terceiro século, é já no século II d.C. que se pode notar, de um ponto de vista político-institucional, o início de uma estrutura de longa duração histórica que permaneceria até o século VIII e caracterizaria toda a Antiguidade Tardia: a constante divisão da autoridade imperial através de diferentes maneiras: burocratização, reformulação ideológica, da formação de diarquias, tetrarquias, divisão entre impérios ocidental e oriental, ou até mesmo pela concessão de autoridade a reis e chefes militares bárbaros.

O Capítulo I, intitulado Os Antecedentes: O Principado e os primeiros sinais de crise político-institucional no mundo romano, aborda o "Período de Ouro" do Império Romano (98-198), relatando sobre os antecedentes da Crise mencionada, a Crise em si e suas conseqüências. Nesse capítulo, Frighetto aponta para várias medidas que foram sendo tomadas durante o período em questão que deram início aos grandes problemas a serem resolvidos no século III: O crescente número de incursões bárbaras que obrigaram as legiões a se tornarem fixas e começarem a praticar o recrutamento local, permitindo, desse modo, a inserção de bárbaros nas legiões romanas; o crescimento do poder das províncias, que passariam a reivindicar maiores poderes e participar do Senado, causando certa instabilidade política; e crescimento da burocra- 
tização para um maior controle de todo o território, o que inevitavelmente acarretou em um aumento de impostos e do número de cargos administrativos, ao mesmo tempo em que os príncipes procuravam concentrar mais poderes em suas mãos, reduzindo a importância do Senado de modo sutil. Além do mais, o príncipe passava a exercer cada vez mais um poder de cunho militar, e com o tempo a eficiência de um príncipe começou a ser medida não somente por sua capacidade administrativa, mas também pela sua capacidade militar em conter os avanços bárbaros. Trajano quebrou com a sucessão imperial por meio da hereditariedade, o que deu início a um efeito cascata de instabilidades na sucessão, que culminariam na chamada "Anarquia Militar", abordada no capítulo seguinte.

O Capítulo II, A Crise do Sistema Polis/Civitas, a regionalização e a fragmentação do poder político imperial no século III, inicia tratando da Dinastia dos Severos (193-235 d.C.) e depois da Anarquia Militar (235-284 d.C.). A Dinastia dos Severos foi marcada por um grande aumento na importância da aceitação do príncipe por parte das legiões, tanto que muitos benefícios - aumento de soldo, oportunidades de ingresso no Senado a partir do exército, recrutamento de bárbaros, dentre outros - foram concedidos aos exércitos durante esse período. Também durante o principado dos Severos se deram as primeiras divisões do poder imperial pela nomeação de mais de um Augusto - sendo um sênior e os outros juniores - numa tentativa de se manter uma presença imperial ativa em um território tão vasto. Também foi realizada uma extensão da cidadania romana, que passou a contemplar todos os homens e 
mulheres livres, para aumentar a arrecadação de impostos, necessária para a manutenção dos exércitos.

No entanto, insatisfações legionárias acabaram culminando na “Anarquia Militar”, período em que houve uma grande quantidade de usurpações, assassinatos de príncipes, aclamações por parte das legiões e instabilidade política no Império Romano: o príncipe que apresentasse debilidades militares era rapidamente eliminado e substituído. Dentre os muitos assassinatos e reposições de príncipes, os setores políticos e ideológicos seguiram se readequando, sendo que paulatinamente se observa uma sacralização definitiva da figura do príncipe, seguida de editos que obrigavam o culto imperial e a perseguição e confisco de bens dos que se recusavam a realizar tal culto. De um ponto de vista político, observase finalmente a tolerância da existência de usurpadores por parte do Augusto romano, diante de sua incapacidade de reconquistar territórios perdidos: atitude que depois culminaria na partilha definitiva e igualitária dos poderes entre mais de um Augusto, configurando a renovação imperial que viria para acabar com a "anarquia".

No capítulo III, A Renouatio Imperii: Diarquia, Tetrarquia e a nova configuração do Império Romano Tardio, Frighetto explica que a "renovação", num ponto de vista político e ideológico, se baseava sempre em tradições antigas, já que “(...) cada uma delas [as renovações] tinha a intenção de recuperar a grandeza do passado imperial romano, travestindo-o com o manto de "novas" interpretações políticas e ideológicas" (FRIGHETTO, 2012, p. 93). Num primeiro momento (entre 286 e 293), observa-se a divisão do poder imperial em dois (diarquia), sendo 
os dois imperadores escolhidos de acordo com sua capacidade militar, exercendo lideranças regionais. Num segundo momento (após 293), um imperador secundário (César) é escolhido por cada imperador principal, formando a tetrarquia. Com a formação da tetrarquia, a divisão entre Ocidente e Oriente romano ocorre de modo irreversível, e o Império Romano adota uma atitude conservadora, e não mais conquistadora, em relação aos seus territórios. O cristianismo, em 313, com a promulgação do Édito de Milão, passa a ganhar nova projeção e se torna uma ferramenta política unificadora: no ano de 380 foi promulgado o Édito de Tessalônica, que definia o cristianismo católico como verdadeiro e a obrigatoriedade de submissão de todas as igrejas a tal, e depois em 392, outro Édito de Milão foi promulgado, que proibia cultos pagãos.

No Capítulo IV, intitulado Da Barbárie à Civilização: os bárbaros e a sua integração no mundo imperial romano (séculos IV-VIII), Frighetto aborda a tomada dos territórios ocidentais pelos reinos bárbaros, e explica sucintamente os eventos que juntos resultaram na configuração política que caracterizaria o início da Idade Média. Tais reinos, já desde fins do século IV, apresentavam maior organização política, militar e diplomática, e a partir do século V passarão a interagir com o Império Romano de modo muito mais colaborativo, em oposição ao antagonismo intenso de séculos anteriores. Alguns reinos passarão, no período abordado no capítulo, a adquirir autonomia em relação à autoridade imperial, como os Visigodos, estabelecendo-se em Tolosa (atual Toulouse, França). 
A reformulação religiosa passou a legitimar o agora Príncipe Cristão Sacratíssimo, e tal legitimação foi depois estendida aos reis bárbaros que viriam a aparecer e adotar o cristianismo como porta de entrada para as boas relações com a autoridade Imperial. O Papa, principal bispo católico de Roma, já surge como uma autoridade; não ainda com todo o prestígio que viria a ter em séculos futuros, mas já importante do ponto de vista político e ideológico: um bom exemplo disso foi a participação do Papa Leão I nas negociações de paz com Átila, o Huno, em 452 .

Os Ostrogodos se instalaram na Itália após a desaparição da figura imperial o ocidente, em 476. Depois, foram derrotados com dificuldade pelo Oriente Romano, que se encontrou, após a vitória, em uma frágil situação econômica, uma vez que sua vitória, veio a custo de muitas mortes e recursos, abrindo espaço para que os Lombardos, que haviam lutado ao lado do Oriente Romano, se instalasse na Itália e fundasse uma série de ducados regionais.

Os Francos, antes fragmentados em várias tribos, elegeram um rei em 481, que procuraria unificar seu povo e se converteria ao catolicismo. Visto como um concorrente dos Visigodos pelo Império Romano Oriental, os Francos rapidamente fizeram aliança com o Oriente Romano, e participaram de diversas campanhas ao lado do Oriente, como na derrota dos Lombardos, em 756. Nos séculos VII e VIII os Francos obtiveram grande projeção e deram início a um processo de restauração da autoridade imperial do Ocidente, só que desta vez, cristão. 
Como algumas considerações finais sobre o livro de Frighetto, pode-se dizer que o mesmo é sem dúvida um ótimo ponto de partida para o estudo da Antiguidade Tardia: contém mapas políticos dos principais momentos históricos, um índice onomástico e glossário, para que o leitor esteja ciente dos conceitos principais. O fim do livro conta também com uma tábua cronológica, para que o leitor se situe com mais facilidade, a partir dos principais eventos, num período complexo e muitas vezes confuso que é a Antiguidade Tardia. O livro também possui um anexo de extratos de fontes manuscritas, que permitem ao leitor ter uma noção dos tipos de documentos que eram escritos, a partir dos quais os estudos sobre a Antiguidade Tardia são feitos.

Vale relembrar que a Antiguidade Tardia é um período extremamente complexo, amplo, e aborda uma territorialidade imensa, e que o livro de Frighetto tem seu foco em questões políticas, institucionais e ideológicas; é de se esperar, portanto, que muitas questões de cunho social não estejam presentes no livro. No entanto, Frighetto deixa uma boa lista de referências que podem ser consultadas para o leitor interessado em expandir seu conhecimento para tais questões. Ademais, levando em conta as dificuldades do tema abordado, seria impossível que um livro só contivesse tanta informação. Tal complexidade presente na Antiguidade Tardia, no entanto, é o que cativa alguns historiadores, que, como Frighetto, percebem neste período único oportunidades de pesquisa intrigantes e virtualmente infinitas. 